\title{
Tracking the potyviral P1 protein in Nicotiana benthamiana plants during plum pox virus infection
}

\author{
Z. VOZÁROVÁ, M. GLASA, Z. W. ŠUBR*
}

Institute of Virology, Biomedical Research Centre, Slovak Academy of Sciences, 84505 Bratislava, Slovakia

Received May 18, 2017; accepted July 04, 2017

\begin{abstract}
Summary. - The P1 protein is derived from the $\mathrm{N}$ terminus of potyvirus-coded polyprotein. In addition to the proteolytic activity essential for its maturation, it probably participates in suppression of host defense and/ or in virus replication. Clear validation of the P1 in vivo function(s), however, is not yet available. We applied an infectious cDNA clone of plum pox virus (PPV), where the P1 was N-fused with a hexahistidine tag, to trace this protein in Nicotiana benthamiana plants during the PPV infection. Immunoblot analysis with the anti-his antibody showed a diffuse band corresponding to the molecular weight about $70-80 \mathrm{kDa}$ (about twice larger than expected) in the root samples from early stage of infection. This signal culminated on the sixth day post inoculation, later it rapidly disappeared. Sample denaturation by boiling in SDS before centrifugal clarification was essential, indicating strong affinity of P1-his to some plant compound sedimenting with the tissue and cell debris.
\end{abstract}

Keywords: potyvirus; his-tag fusion; immunoblotting

Genome expression of the plum pox virus (PPV, the genus Potyvirus) is based on the "polyprotein strategy“. Particular polyprotein-derived polypeptides are multifunctial and participate in various processes including viral RNA replication, polyprotein processing, inhibition of posttranscriptional gene silencing, cell-to-cell and systemic movement, encapsidation and assistance at vector-based transmission (Šubr and Glasa, 2013). The N-proximal P1 protein is believed to be involved in suppression of host defense (Valli et al., 2006), in virus replication (Pasin et al., 2014) or stimulation of viral proteosynthesis (Martínez and Darós, 2014), however, its detailed function and mechanism of action during infection cycle remain unknown. Here we tried to trace the viral P1 in the systemic host Nicotiana benthamiana during an experimental PPV infection.

The infectious cDNA clone pIC-PPV-Rec (Predajňa et al., 2012) was modified by inserting the sequence coding for six histidine residues between the fourth and fifth amino acid of the $\mathrm{P} 1$ protein. This was performed using specific primers in

"Corresponding autor. E-mail: Zdeno.Subr@savba.sk; phone: +421-2-59302-447.

Abbreviations: $\mathrm{PPV}=$ plum pox virus two separate PCR resulting in overlapping fragments, which were then combined by another amplification step (Table 1). Final product was sequence-verified and replaced for the homologous region in the cDNA clone by PvuI-RsrII restriction/ligation to gain the construct PIC-PPV-Rec-P1His.

$N$. benthamiana plants were transfected biolistically using a previously developed air-gun system (Predajňa et al., 2010). Three weeks later, PPV was proved in the plants by immunoblotting and the presence of modified virus was verified by PCR and sequencing. The virus was further passaged by mechanical inoculation. Samples from various plant parts (inoculated and non-inoculated leaves, stems, apical parts and roots) were collected at various time-points after infection and analysed by immunoblotting with anti-histidine antibodies (Sigma). The tissues were grinded by mortar and pestle in PBS pH $7.4(1: 2, \mathrm{w}: \mathrm{v})$ and subsequent denaturation step ( 5 min boiling in the SDS-PAGE sample buffer) was performed either before or after centrifugal removal of the cell and tissue debris (5 min at 16,000 $\mathrm{x} \mathrm{g}$ ).

The PPV with his tag-fused P1 was able to replicate in $N$. benthamiana and it remained stable during several mechanical passages of the virus. Ten days post inoculation (dpi), the viral capsid protein was clearly detectable 
Table 1. Primers and PCR conditions used for construction of pIC-PPV-Rec-P1His

\begin{tabular}{|c|c|c|c|c|}
\hline Primer (position) ${ }^{1}$ & Sequence $^{2}$ & Template & PCR conditions ${ }^{3}$ & $\begin{array}{c}\text { Amplimer } \\
\text { (length) }\end{array}$ \\
\hline $\begin{array}{l}\text { VekFor } \\
(12869-12889)\end{array}$ & ATTAATGCAGCTGGCTTATCG & pIC-PPV-Rec & $\begin{array}{l}\mathrm{T}_{\mathrm{a}} 56^{\circ} \mathrm{C} \\
\mathrm{t}_{\mathrm{e}} 2 \mathrm{~min}\end{array}$ & $\begin{array}{c}1 \\
(1509 \mathrm{bp})\end{array}$ \\
\hline $\begin{array}{l}\text { 6hisP1rev } \\
(137-161)\end{array}$ & $\begin{array}{l}\text { TACgtggtggtggtggtggtgAATGGTTG } \\
\text { ACATCTTGACTTGC }\end{array}$ & & & \\
\hline $\begin{array}{l}\text { 6hisP1for } \\
(156-179)\end{array}$ & $\begin{array}{l}\text { ATTcaccaccaccaccaccacGTATTTGGCTCA } \\
\text { TTCACTTGC }\end{array}$ & pIC-PPV-Rec & $\begin{array}{l}\mathrm{T}_{\mathrm{a}} 56^{\circ} \mathrm{C} \\
\mathrm{t}_{\mathrm{e}} 40 \mathrm{~s}\end{array}$ & $\begin{array}{c}2 \\
(453 \mathrm{bp})\end{array}$ \\
\hline $\begin{array}{l}\text { BorRArev } \\
(569-590)\end{array}$ & AGGTTTCTCAATAATATGAGGG & & & \\
\hline VekFor & as above & amplimer 1 & $\mathrm{~T}_{\mathrm{a}} 56^{\circ} \mathrm{C}$ & 3 \\
\hline BorRArev & as above & $\stackrel{+}{\text { amplimer } 2}$ & $\mathrm{t}_{\mathrm{e}} 2.5 \mathrm{~min}$ & (1920 bp) \\
\hline
\end{tabular}

${ }^{1}$ Position numbered according to pIC-PPV-Rec (Predajňa et al., 2012); ${ }^{2}$ inserted linker coding for hexahistidine tag is represented by lower case letters; ${ }^{3} \mathrm{~T}_{\mathrm{a}}=$ annealing temperature, $\mathrm{t}_{\mathrm{e}}=$ elongation time.

in all inspected plant parts independently on the sample preparation method. Anti-his antibody, however, gave only weak diffuse signal in immunoblot (prolonged incubation with the substrate was needed, resulting in a relatively high background), which became much stronger in root samples when the denaturation step preceded the centrifugal clarification (Fig. 1a). Similar behavior has been recently described for in planta expressed PB1-F2 protein of influenza virus, known to create insoluble amyloid fibres (Kamencayová et al., 2014). Therefore we presume P1-his low solubility either as its intrinsic feature, or as a result of its affinity to some plant compound sedimenting with the debris.

The observed diffuse band from the root samples corresponded to molecular mass between $70-80 \mathrm{kDa}$, which was about twice higher than expected $(\approx 36 \mathrm{kDa})$. This might be due to any posttranslational modifications (including covalent dimerisation). An atypical release from the polyprotein cannot be excluded, too, although the $\mathrm{P} 1$ protease domain is located on its C terminus (Valli et al., 2007) and is unlikely to be affected by the $\mathrm{N}$-proximal fusion partner. At least partial purification will be needed for further characterisation of this polypeptide. Interestingly, no (or very weak) reaction with anti-histidine antibody was observed in samples from other plant tissues, while the root sample was clearly positive during the early infection stage. It may be caused by extremely fast degradation of $\mathrm{P} 1$ in the green parts in vivo or during sample preparation. Even in root samples, the turnover of $\mathrm{P} 1$ was very fast. The signal strength culminated at $6 \mathrm{dpi}$, later it rapidly disappeared (Fig. 1b). Twin-Strep tag-fused P1 of Tobacco etch potyvirus has been proved in systemically infected leaves of $N$. benthamiana and its appearance during early stage of infection correlated very well with our results (Martínez and Darós, 2014).

$\mathrm{P} 1$ is the most divergent potyviral protein, therefore its role in specific interactions with particular host factors has

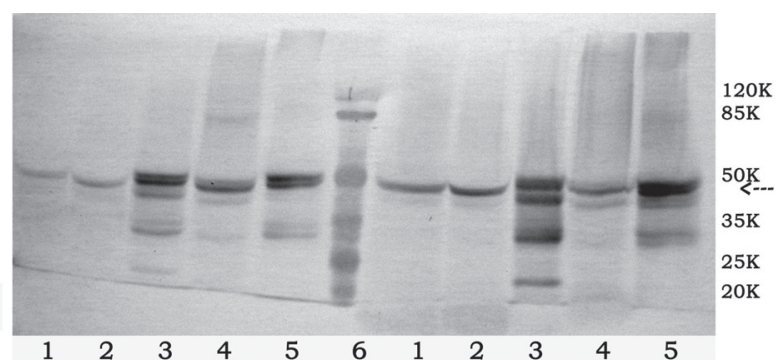

(a)

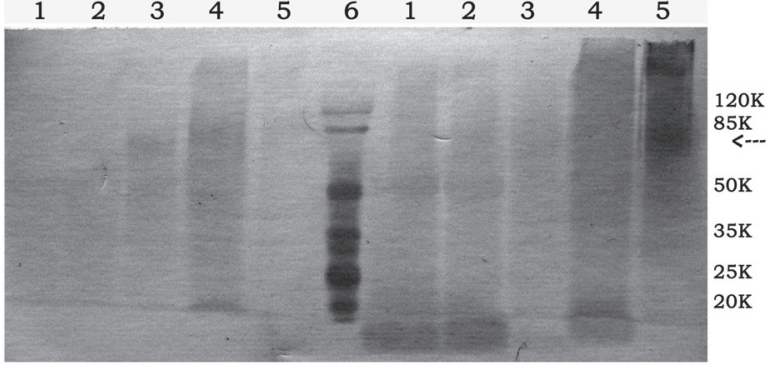

(b)

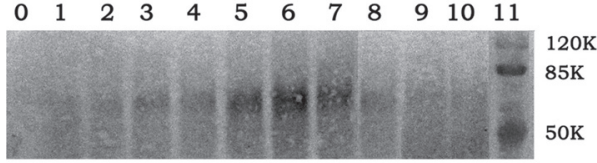

Fig. 1

Detection of PPV P1-his in different plant parts

(a) Immunoblotting analysis of samples collected $8 \mathrm{dpi}$, using anti-PPV (top) and anti-his (bottom) antibodies. Lanes 1 - inoculated leaf, lanes 2 non-inoculated leaf, lanes 3 - top apex, lanes 4 - stem, lanes 5 - root, lane 6 - molecular weight marker (values on the right). The arrows show the positions of intact capsid protein and P1-his, respectively. The samples were denatured after clarification (left from the marker), or before clarification (right from the marker). (b) Immunoblotting analysis of root samples collected during early stage of infection by pIC-PPV-Rec-P1His using anti-his antibodies. Lane 0 - healthy control, lanes 1-10 - collection time 1-10 dpi, lane 11 - molecular weight marker (values on the right). The samples were denatured before clarification. 
been anticipated. It influences the symptom manifestation (Nagyová et al., 2012; Maliogka et al., 2012) and host specifity (Salvador et al., 2008), however, only speculations about the mode of its action in vivo are still at disposal. There are indicia that it cooperates with other potyviral protein (HCpro) in suppression of host gene silencing defense (Valli et al., 2006) or interacts with ribosomes to stimulate viral protein synthesis at the expense of the host own one (Martínez and Darós, 2014). Knowledge about expression kinetics and localisation of P1 in vivo contributes to the comprehensive image of its real role during potyviral infection.

Acknowledgements. The research was supported by the grant 2/0001/15 from the Scientific Grant Agency of Ministry of Education and Slovak Academy of Sciences (VEGA).

\section{References}

Šubr Z, Glasa M (2013): Unfolding the secrets of plum pox virus: from epidemiology to genomics. Acta Virol. 57, 217-228. https://doi.org/10.4149/av_2013_02_217

Valli A, Martin-Hernandez AM, Lopez-Moya JJ, Garcia JA (2006): RNA silencing suppression by second copy of the P1 serine protease of Cucumber vein yellow ipomovirus (CVYV), a member of the family Potyviridae that lacks the cysteine protease HC-Pro. J. Virol. 80, 10055-10063. https://doi.org/10.1128/JVI.00985-06

Pasin F, Simón-Mateo C, García JA (2014): The Hypervariable Amino-Terminus of P1 Protease Modulates Potyviral Replication and Host Defense Responses. PLOS Pathogens 10, e1003985. https://doi.org/10.1371/journal.ppat.1003985

Martínez F, Darós JA (2014): Tobacco Etch Virus Protein P1 Traffics to the Nucleolus and Associates with the Host 60S Ribos- omal Subunits during Infection J. Virol. 88, 10725-10737. https://doi.org/10.1128/JVI.00928-14

Predajňa L, Nagyová A, Glasa M, Šubr Z (2012): Cloning of the complete infectious cDNA of the Plum pox virus strain PPV-Rec. Acta Virol. 56, 129-132. https://doi. org/10.4149/av $201202 \quad 129$

Predajňa L, Nagyová A, Šubr Z (2010): Simple and efficient biolistic procedure of plant transfection with cDNA clons of RNA viruses. Acta Virol. 54, 303-306. https://doi.org/10.4149/ av $2010 \quad 04 \quad 303$

Kamencayová M, Košík I, Hunková J, Šubr ZW (2014): Transient expression of the influenza A virus PB1-F2 protein using a Plum pox virus-based vector in Nicotiana benthamiana. Acta Virol. 58, 274-277. https://doi.org/10.4149/ av $2014 \quad 03 \quad 274$

Nagyová A, Kamencayová M, Glasa M, Šubr ZW (2012): The 3'proximal part of the Plum pox virus $\mathrm{P} 1$ gene determinates the symptom expression in two herbaceous host plants. Virus Genes 44, 505-512. https://doi.org/10.1007/s11262$\underline{012-0726-9}$

Maliogka VI, Salvador B, Carbonell A, Sáenz P, San León D, Oliveros JC, Delgadillo MO, García JA, Simón-Mateo C (2012): Virus variants with differences in the P1 protein coexist in a Plum pox virus population and display particular host-dependent pathogenicity features. Mol. Plant Pathol. 13, 877-886. https://doi.org/10.1111/j.13643703.2012.00796.x

Salvador B, Sáenz P, Yanguez E, Quiot J B, Quiot L, Delgadillo MO, García JA, Simón-Mateo C (2008): Host-specific effect of P1 exchange between two potyviruses. Mol. Plant Pathol. 9, 147-155. https://doi.org/10.1111/j.1364-3703 $.2007 .00450 . x$

Valli A, López-Moya JJ, García JA (2007): Recombination and gene duplication in the evolutionary diversification of P1 proteins in the family Potyviridae. J. Gen. Virol. 88, 1016-1028. https://doi.org/10.1099/vir.0.82402-0 